\title{
High-Power Fibre Laser Cleaning for Green Shipbuilding
}

\author{
G. X. Chen ${ }^{* 1}$, T. J. Kwee ${ }^{* 1}$, K. P. Tan ${ }^{* 1}$, Y. S. Choo ${ }^{* 2}$, and M. H. Hong ${ }^{* 2}$ \\ ${ }^{* 1}$ Centre of Innovation (Marine \& Offshore Technology), Ngee Ann Polytechnic, Singapore 599489 \\ ${ }^{*}$ Faculty of Engineering, National University of Singapore, Singapore 117576 \\ E-mail: elehmh@nus.edu.sg
}

\begin{abstract}
Blasting techniques in shipbuilding and ship repair have been developed for surface preparation of steel to a standard equivalent to SA2.5 as defined by ISO Standard 8501. The usage of consumables, such as abrasive materials, air and water, constitutes a recurring cost in these processes. When blasting work is carried out in the open space, such as during a dry docking, abrasive blasting generates a lot of dusts which in turn pollutes the environment with consequential social and economical costs. Laser blasting or laser cleaning, which has not been introduced commercially in shipbuilding and ship repair, offers an alternative for green manufacturing and green repairs. Laser cleaning has significant advantages on these issues over the conventional blasting techniques. It is a wellcontrolled process with unique properties, such as precise treatment, high selectivity, and high flexibility. A cleaning technique using a high-power fibre laser is developed for the surface preparation of steel. Fibre laser has advantages of compact system, automation capability, and low maintenance cost. We report the laser cleaning results using a 500-W pulsed high-power fibre laser. The laser cleaning is able to meet the SA 2.5 requirements of blast cleaning as described in the International Organization for Standardization (ISO) standard 8501.

DOI:10.2961/jlmn.2012.03.0003
\end{abstract}

Keywords: Pulsed fibre laser, laser ablation, blasting cleaning technique, laser cleaning, shipyard.

\section{Introduction}

Corrosion is a severe problem for marine vessels and offshore structures built in steel working in sea water and harsh environmental conditions. Corrosion of hull steel causes billion-dollar losses every year [1]. Serious corrosion can lead to ship damage and accidents. To prevent corrosion of steel surfaces, it is important to have a good surface preparation prior to the application of marine coatings. The paint films build up a barrier to prevent corrosive seawater from directly contacting with the steel surface of a hull. The quality of paint is a significant factor that affects the protection performance. The painting processes and the associated pre-painting works also play important roles in preventing corrosion. In particular, pre-painting works, commonly surface cleaning of steel plates, are necessary steps for the painting work with considerable impact on protection performance.

Surface cleaning methods for shipbuilding and ship repair are well established. The most popular cleaning method is dry blasting which is often conducted by ejecting abrasives, such as grit, from copper slag or similar abrasive and reusable steel shots against steel work pieces to achieve blasting standard of at least SA2.5 as required by the ISO standard 8501 [2]. The normal air pressure required for blasting is at least 7 bars. The strong impingement of abrasives with the surface removes millscale, rust, paints and other organic coatings to give a clean surface. But dry blasting processes often produce air pollution and secondary wastes where copper slag or similar abrasives have been used. The use of copper slag or equivalent abrasive materials and their disposal annually cost million dollars for shipyards. The dirty environment arising from dusts of various particle sizes resulting from blasting work also exposes health risks to operators and the general public. In order to solve these problems, alternative cleaning methods, such as hydro-blasting and hydro-jetting have been developed and used in ship repairs. But these methods have not gained universal acceptance by ship owners as these cleaning processes require the use of more expensive waterbased epoxy coating systems.

Surface cleaning using a laser has been studied and successfully implemented in semiconductor manufacturing industries [3]. Laser cleaning for the removal of coatings and contaminants was investigated for the aerospace industry [4]. New laser cleaning application of treating rust was reported by Daurelio et al using a Q-switched Nd:YAG laser at different pulse repetition rates [5]. Laser cleaning also provides the possibility to meet the surface cleaning requirements of shipbuilding and ship repairs with economic and ecological benefits. We have investigated the laser removal of paint films from steel plates using a $\mathrm{CO}_{2}$ laser [6], laser cleaning of steel plates using a fibre laser [7], and underwater laser removal of crude oil [8]. Surface oxide layers, contaminants and coatings on steel plates were completely removed under the exposure of a high-power laser [9-11]. The cleaning quality of the laser processed samples can meet the requirements of shipbuilding and ship repairs [10].

Laser cleaning systems based on $\mathrm{CO}_{2}$ laser from 4JET Technologies $\mathrm{GmbH}$ and General Lasertronics Corporation, and Nd:YAG laser from Clean Lasersysteme GmbH, Quanta System, Quantel, Lynton and General Lasertronics Corporation have been made commercially available. But for laser cleaning applications in marine and offshore industry, it requires quicker start-up, improved optical performance, 
more compact footprint, more flexible design, longer uptime, lower operation and maintenance costs. The new comer to the laser market, high-power pulsed fiber laser, can meet this requirement perfectly. In this work, we report the cleaning performance and cleaning results of hot-rolled steel plates with millscale using a specially customized high-power fibre laser. This is the first 500-W pulsed fibre laser in the world released by IPG Photonics.

High-power Nd:YAG laser removal of loose rust has been reported [12]. Few publications have investigated laser cleaning of millscale protected steel plates. The effects of laser parameters, such as scanning pass, on the cleaning efficiency, are investigated in details.

\section{Experimental}

The samples covered with millscale are as-received hot-rolled mild steel plates. Laser cleaning of different contaminants, such as rust, paint, salt, crude oil, and grease were also studied. The rusted samples were prepared by leaving the steel plates at wet outdoor environment for a few weeks. Other contaminants were spread over the steel plates before the laser treatment. The laser processing system is illustrated in Fig. 1. The multimode laser beam from a high-power pulsed fibre laser (IPG Photonics, YLP-HP30-400-16-500-SG) is transmitted in an optical fibre. The beam is collimated into a scanner head for processing the steel samples. The laser has a wavelength range from 1055 to $1075 \mathrm{~nm}$ with a central emission wavelength of $1064 \mathrm{~nm}$. The maximum output power is $500 \mathrm{~W}$. The maximum pulse energy is $31 \mathrm{~mJ}$. The pulse repetition rate can be set from 2 to $50 \mathrm{kHz}$. The pulse energy can be changed by varying laser power or pulse repetition rate. Laser beam is focused through an F- $\theta$ lens to a spot diameter of $0.4 \mathrm{~mm}$ on the sample surface. The moving speed of laser beam over steel samples was varied from 1 to $15 \mathrm{~m} / \mathrm{s}$ at a typical speed of $10 \mathrm{~m} / \mathrm{s}$. The spacing between laser processing lines was programmed from 0.05 to $0.4 \mathrm{~mm}$. The maximum processing area covered per scan is $70 \times 70 \mathrm{~mm}^{2}$. The samples were fixed on a workbench for cleaning small areas below the maximum processing area, while moved on a belt conveyer for cleaning larger areas. A high-power fan-cooled thermal sensor (Ophir, FL500A) and a power meter (Ophir, Nova) were used to monitor the laser power. The surface temperature of the steel samples was determined with an infra-red thermometer (Paler Wahl, DHS215XEL). The fume and dust generated during the laser cleaning were collected with a laser fume extractor (Bofa, AD Oracle). The visually cleaning quality was measured with the surface roughness and the reflection. The elemental analysis of the samples was done with a SEM and an Energydispersive X-ray spectroscope (EDX).

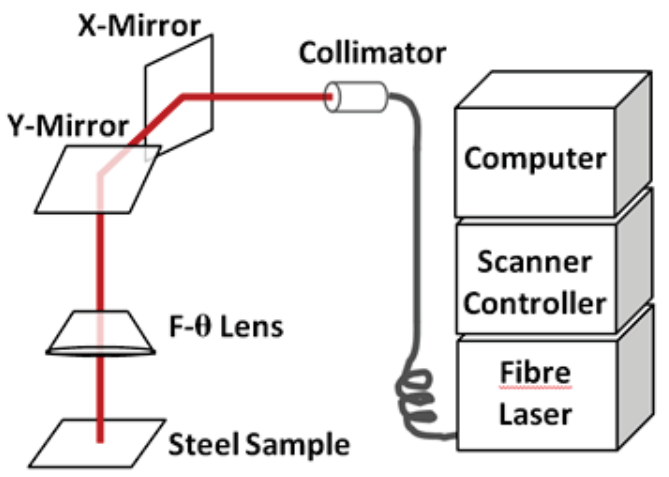

Fig. 1 Schematic diagram of experimental setup.

\section{Results and Discussion}

The surface contaminants usually cover steel plates at a thickness ranging from a few to hundreds of micrometers. In this work, the millscale has a thickness around $30 \mu \mathrm{m}$. As shown in Fig. 2 (a), it has a rough surface with microcracks and a number of small protrusions. The cracking of millscale causes pitting corrosion to the base steel and further cracking to the paint. Therefore, the millscale must be completely removed for corrosion protection. To remove the millscale layer, the ablation rate is an important parameter to be taken into consideration. Our previous study showed that the ablation rate decreases greatly with the laser scanning speed [7]. High scanning speeds $(\geq 10 \mathrm{~m} / \mathrm{s})$ provide uniform removal of the millscale layer at a constant surface roughness around $20 \mu \mathrm{m}$. But the removal rate is as low as $2 \mu \mathrm{m}$ per scan pass. Figure 2 (b) displays a 2pass scanning result. The surface roughness is obviously reduced by the melting and ablation of the millscale layer. The cracks disappear, while the small protrusions are melted. To completely clean the millscale layer, multiple scan passes up to 20 times are needed as shown in Fig. 2 (c). The small protrusions are removed to form a relatively smooth surface. There are vertical micrometer-scale grooves created during the repetitive laser scanning and ablation. The pitch of these micro-grooves is around 0.4 $\mathrm{mm}$, which is in consistent with the scanning line density for the setting of the laser process. The depth of grooves can be adjusted by changing laser scanning speed and pulse energy. The typical profile depth of the processed grooves is in the range of 30 to $80 \mu \mathrm{m}$. To provide a strong adhesion of paint films to the steel surface, the surface preparation of shipbuilding work often requires a profile depth from 45 to $75 \mu \mathrm{m}$. Current results can meet this requirement by properly setting the laser parameters.

Intense laser irradiation gives rise to quick evaporation of surface materials. The maximum laser power density used in this study is around $60 \mathrm{MW} / \mathrm{cm}^{2}$. All the contaminants mentioned above can be cleaned by ablation and plasma detonation [13]. The steel surface after the laser treatment has a layer of uniform nanostructures at a size below $100 \mathrm{~nm}$ as shown in Fig. 2 (d). The surface property was characterized with a water contact angle test. It shows a hydrophilic surface, which indicates the complete removal of the oil and the grease. The removal performance of the paint is similar to our previous study using a $\mathrm{CO}_{2}$ laser [6]. The samples after the laser cleaning show no trace of 
paint when being measured by a laser Raman spectroscope. Other contaminants, such as dust, salt and loose rust, can be easily removed by laser ablation generated shockwave and then extracted away by the laser fume extractor.

The cleanliness of the laser processed samples was characterized with the EDX spectra as illustrated in Fig. 3. As displayed in Fig. 3 (a), the EDX spectrum of original surface shows the feature peaks of oxygen, sulfur and a minor peak of carbon. In Fig. 3 (b), after the laser cleaning for 2 passes, the feature peaks of iron grows, while sulfur peak disappears. The increase of the oxygen peak suggests that the top layer of contaminants was removed, and more oxides were exposed. When the processing pass reaches 20 times, the iron peaks overwhelm in the EDX spectrum as shown in Fig. 3 (c). It implies a thoroughly cleaned steel surface is obtained.
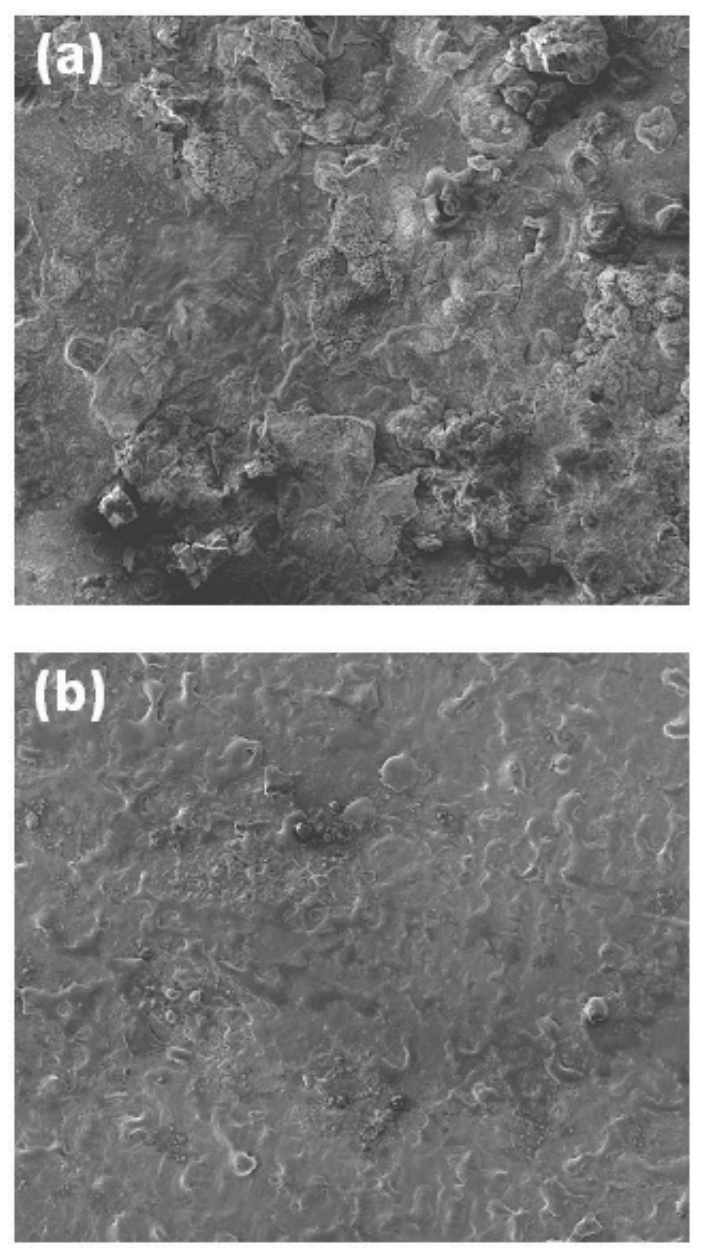
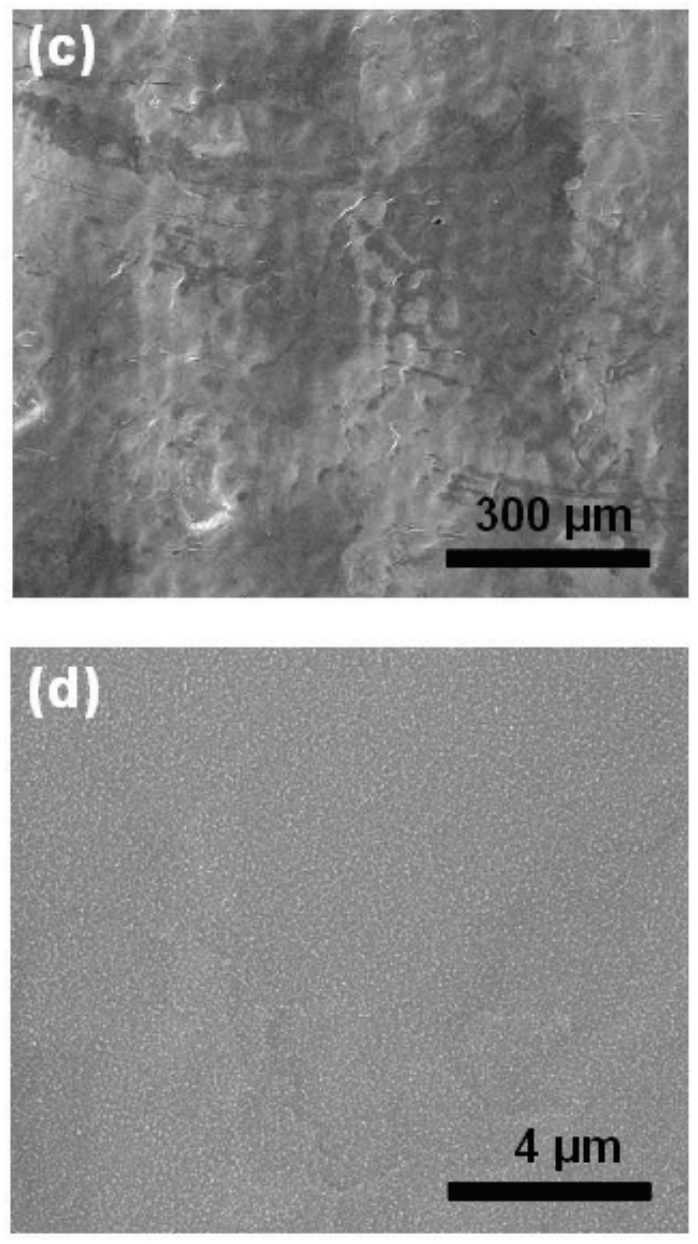

Fig. 2 SEM images of steel samples prepared at different scanning passes: (a) 0 (original surface), (b) 2 and (c) 20 time scans. The scale bars of images $(\mathrm{a}-\mathrm{c})$ are the same size. Image (d) is magnified from (c).

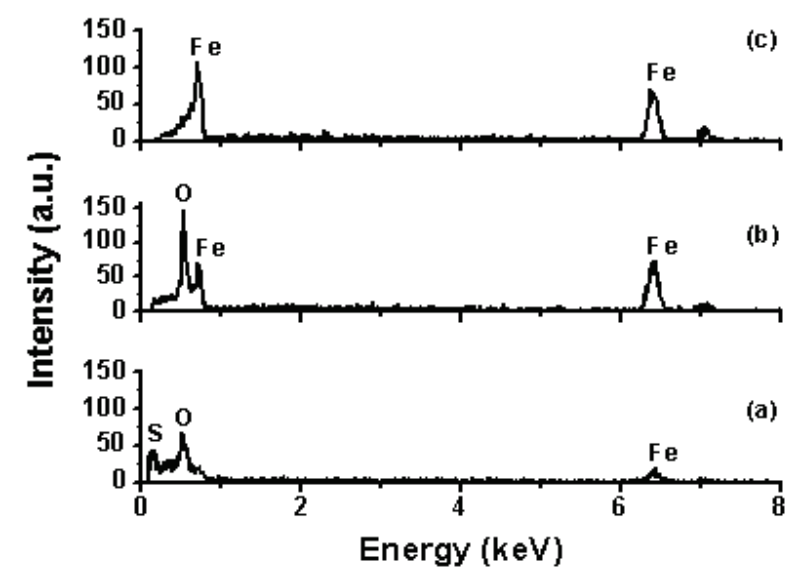

Fig. 3 EDX spectra of steel samples prepared at different scanning passes: (a) 0 (original surface), (b) 2 and (c) 20 time scans. 


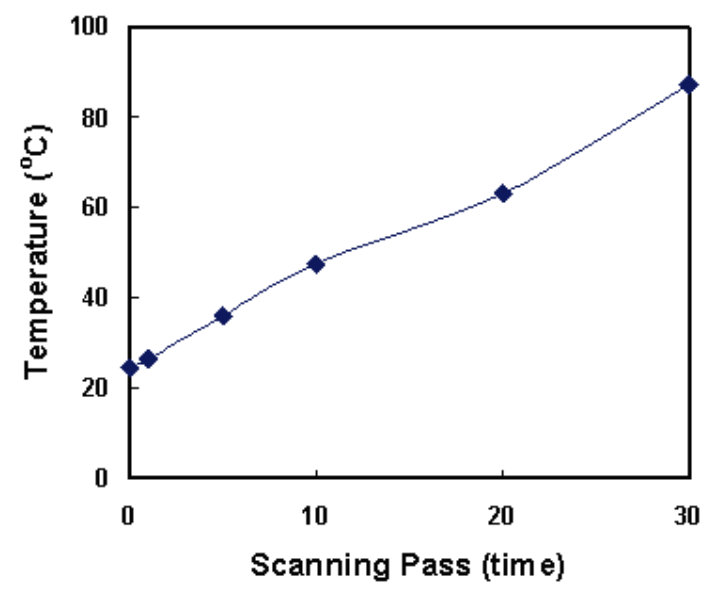

Fig. 4 Surface temperature after the laser processing.

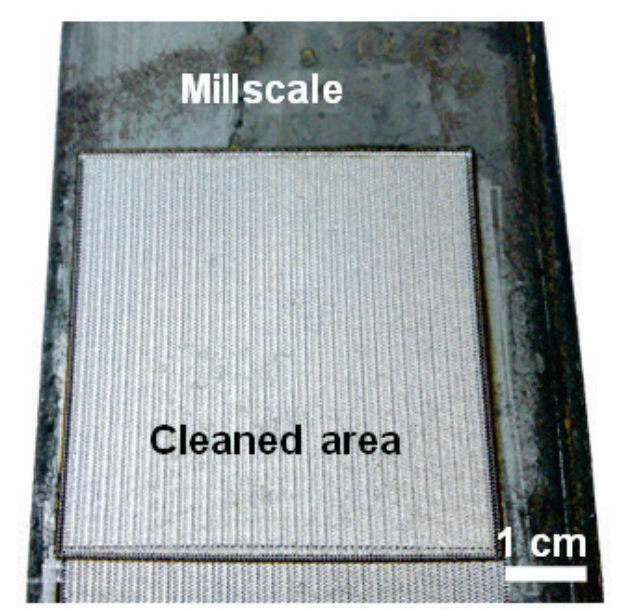

Fig. 5 Photo of a steel sample prepared by the laser cleaning. The sample was stored in ambient air for 6 months, which shows no rusting being formed.

Laser beam is focused into a tiny spot so that the laser power density is high enough to vaporize the materials. But the intense laser interaction with materials leads to strong heating of the base materials [13]. With presence of oxygen, steel samples could be thermally oxidized at high surface temperatures. For the laser cutting processes, we often observe darken surfaces that were caused by the thermal oxidation. This concurrent oxidation may cause problems for the cleanliness quality of the laser cleaning. To avoid the laser generated oxidation, an inert gas is usually used as a protection medium. But it increases the operation cost. Proper laser settings can minimize the occurrence of the thermal oxidation during the laser cleaning process in ambient air. Figure 4 shows the maximum temperature taken in real time during the laser processing. By adjusting laser scanning speed, scanning line density and laser power density, the maximum temperature below $100{ }^{\circ} \mathrm{C}$ was achieved. For a laser scanning pass of 20 times, the maximum temperature is $63{ }^{\circ} \mathrm{C}$. It did not induce serious thermal oxidation as demonstrated in Fig. 3 (c).

The high-power and high repetition rate fibre laser provides a solution for preparing high-cleanliness surfaces of the ship steel. The image shown in Fig. 5 was taken 6 months after the laser cleaning. There is no obvious rusting in the laser cleaned area, while the millscale starts to form rust on the original surface. This cleaning result is comparable to the visual assessment of blast cleaning to SA2.5 as required in the ISO standard 8501 [2]. As different coating thicknesses need different surface profile depths, conventional blasting techniques carry out the process based much on the operator's experience. Laser cleaning is a unique alternative approach for different paint thicknesses ranging from light to heavy-duty protective coatings.

The required blasting rate for shipbuilding and ship repairs demands $60 \mathrm{~m}^{2} / \mathrm{h}$ [14]. Conventional blasting is still the most popular method used in shipyards. More work has to be done using higher power laser systems to explore its commercial potential.

\section{Conclusions}

The experimental results show that the high-power fibre laser can be a promising alternative tool to conventional abrasive blasting equipments. Surface contaminants, including millscale, rust, paint, salt, crude oil, and grease, can be efficiently removed by properly setting the laser processing parameters. SEM and EDX measurements demonstrate that the high cleanliness of steel samples can be achieved by increasing the laser scanning pass. The surface temperature during the laser processing is low enough to minimize the occurrence of oxidation reaction. Laser cleaning can provide high cleanliness and precise surface profiles. As the fibre laser has advantages of low maintenance cost, compact design and flexibility of high power delivery using optical fibres, it would be a promising tool for green surface preparation for shipbuilding industry.

\section{Acknowledgements}

This project is supported by MOE IF Fund MOE2008-IF-1004 .

\section{References}

[1] U.S. Department of the Navy Carderock Division, Naval Surface Warfare Center, and Peterson Builders, Inc., The National Shipbuilding Research Program: Surface Preparation and Coating Handbook, 1994.

[2] ISO 8501-1, Preparation of steel substrates before application of paints and related products -- Visual assessment of surface cleanliness -- Part 1: Rust grades and preparation grades of uncoated steel substrates and of steel substrates after overall removal of previous coatings, International Organization for Standardization, 2007.

[3] M.H. Hong, W.D. Song, Y. F. Lu, B. Luk'yanchuk, and T.C. Chong: Laser Cleaning of Organic Contamination on Microelectronic Devices and Process realtime monitoring, Laser Cleaning (edited by B. Luk'yanchuk, World Scientific Publishing, Singapore, May 2002), pp. 433-464.

[4] SERC Aerospace Programme Brochure, SIMTech, A*STAR, Singapore.

[5] G. Daurelio, G. Chita and M. Cinquepalmi: Proc. SPIE 3097, 369 (1997). 
[6] G.X. Chen, T.J. Kwee, K.P. Tan, Y.S. Choo, and M.H. Hong: Appl. Phys. A 101 (2010) 249.

[7] T. J. Kwee, G. X. Chen, N. R. Lei, K. P. Tan, Y. S. Choo and M. H. Hong: Surface Preparation for Shipbuilding using Pulsed High-Power Fibre Laser, International Congress on Applications of Lasers \& Electro-Optics (ICALEO) 26-30 Sept 2010, Anaheim, CA, USA.

[8] G. X. Chen, T. J. Kwee, N. R. Lei, K. P. Tan, Y. S. Choo and M. H. Hong: Underwater Laser Cleaning for Marine and Offshore Applications, International Congress on Applications of Lasers \& Electro-Optics (ICALEO) 26-30 Sept 2010, Anaheim, CA, USA.
[9] C.A. Cottam and D.C. Emmony: Corrosion Science 41 (1999) 1529.

[10]Z. Sun, J. Xu, and W. Zhou: Proc. SPIE 4915 (2002) 374-377.

[11] M.J.J. Schmidt, L. Li and J.T. Spencer: J. Materials Processing Technology 138 (2003) 109.

[12] Youtube: 1000 Watt Laser Rust Removal, http://www.youtube.com/watch? $\mathrm{v}=0 \mathrm{xxPd} \mathrm{nSVrs}$.

[13] K. G. Watkins: Proc. SPIE 3888 (2000) $1 \overline{6} 5$.

[14] G. D. Schuöcker and R. Bielak: Proc. SPIE 6346 (2007) 634633.

(Received: June 02, 2011, Accepted: June 13, 2012) 